\title{
HARMONIOUS CHROMATIC NUMBER OF CENTRAL GRAPH OF QUADRILATERAL SNAKES
}

\author{
AKHLAK MANSURI ${ }^{1, a}$, ROHIT MEHTA ${ }^{2}$, R. S. CHANDEL ${ }^{1, b}$ \\ ${ }^{1}$ Department of Mathematics, Government Girls College, \\ Mandsaur (M.P.) India, email: ${ }^{a}$ akhlaakmansuri@gmail.com, \\ ${ }^{b}$ rs_chandel2009@yahoo.co.in \\ ${ }^{2}$ Department of Engineering Mathematics, Radharaman Engineering \\ College, Bhopal (M.P.) India, email: rohitmehta1010@gmail.com
}

\begin{abstract}
This article shows the study about the harmonious coloring and investigation of the harmonious chromatic number of the central graph of the $k$ quadrilateral snake and $k$-alternate quadrilateral snake i.e. $\chi_{H}\left(C\left(k Q_{n}\right)\right)=(3 k+$ $2) n-(3 k+1)$ and $\chi_{H}\left(C\left(k\left(A Q_{n}\right)\right)\right)=\left(\frac{3 k+4}{2}\right) n-1$.

Key words and Phrases: Harmonious coloring; harmonious chromatic number; central graph; quadrilateral and alternate quadrilateral snakes.
\end{abstract}

\section{INTRODUCTION}

The harmonious coloring $[6,7,8,17,18]$ of a simple graph $\mathrm{G}$ is a kind of vertex coloring in which each edge of graph $G$ has different color pair and least number of colors are to be used for this coloring is called the harmonious chromatic number, denoted by $\chi_{H}(G)$. For a simple graph $G$ when we subdivide the each edge and connect all the non-adjacent vertices, such obtained graph is called the central graph $[7,17,18]$ of $G$ and it is denoted by $C(G)$. A quadrilateral snake $Q_{n}$ is obtained from a path $u_{1}, u_{2}, \ldots, u_{n}$ by joining $u_{i}$ and $u_{i+1}$ to new vertices $v_{i}$ and $w_{i}$ respectively and adding edges $v_{i} w_{i}$ for $(1 \leq i \leq n-1)$ in which every edge of a path is replaced by a cycle $C_{4}$. We take the following definitions from $[3,4,9,10,11,12$, $13,14,15,16]$ : quadrilateral snake, double quadrilateral snake, triple quadrilateral snake, alternate quadrilateral snake, double alternate quadrilateral snake and triple alternate quadrilateral snake and investigate the harmonious chromatic number of the central graph of these graphs. We also give the harmonious chromatic number of the central graph of $k$ - quadrilateral snake and $k$-alternate quadrilateral snake, where the $k$-quadrilateral snake graph $k\left(Q_{n}\right)$ consists of $k$ quadrilateral snakes

2020 Mathematics Subject Classification: 05C15, 05C76 Received: 11-07-2020, accepted: 12-01-2021. 
with a common path and $k$-alternate quadrilateral snake graph $k\left(A Q_{n}\right)$ consists of $k$ alternate quadrilateral snakes (alternatively) with a common path. $P_{n}$

Throughout the paper we consider $n$ as the number of vertices of the path

\section{Harmonious Chromatic Number of $C\left(Q_{n}\right), C\left(D Q_{n}\right), C\left(T Q_{n}\right)$}

Theorem 2.1. For central graph of quadrilateral snake $Q_{n}$, the harmonious chromatic number, $\chi_{H}\left(C\left(Q_{n}\right)\right)=5 n-4, n \geq 2$.

Proof. Let us consider $Q_{n}$ as the quadrilateral snake graph and $P_{n}$ as the path graph contains $n$ vertices $u_{1}, u_{2}, \ldots, u_{n}$. For obtaining central graph, we subdivide each edge $u_{i} u_{i+1}, u_{i} v_{i}, u_{i} w_{i}$ and $v_{i} w_{i}(1 \leq i \leq n-1)$ of $Q_{n}$ by the vertices $v_{i}^{\prime}$, $v_{i}^{\prime \prime}, v_{i}^{\prime \prime \prime}$ and $v_{i}^{\prime \prime \prime \prime}(1 \leq i \leq n-1)$ of $Q_{n}$ in central graph of $Q_{n} . V\left(C\left(Q_{n}\right)\right)=\left\{u_{i}\right.$ : $1 \leq i \leq n\} \cup\left\{v_{i}, w_{i}, v_{i}^{\prime}, v_{i}^{\prime \prime}, v_{i}^{\prime \prime \prime}, v_{i}^{\prime \prime \prime \prime}: 1 \leq i \leq n-1\right\}$. Now coloring the vertices of $C\left(Q_{n}\right)$ as follows; define $c: V\left(C\left(Q_{n}\right)\right) \longrightarrow\{1,2,3, \ldots, 5 n-4\}$ where $n \geq 2$ by $c\left(v_{i}^{\prime \prime}\right)=i, c\left(v_{i}^{\prime \prime \prime}\right)=i, c\left(v_{i}^{\prime}\right)=n-i+1, c\left(v_{i}^{\prime \prime \prime \prime}\right)=n-1+i, c\left(v_{i}\right)=2 n-2+i$, $c\left(w_{i}\right)=3 n-3+i$ for $(1 \leq i \leq n-1)$ and $c\left(u_{i}\right)=4 n-4+i$ for $(1 \leq i \leq n)$. Now

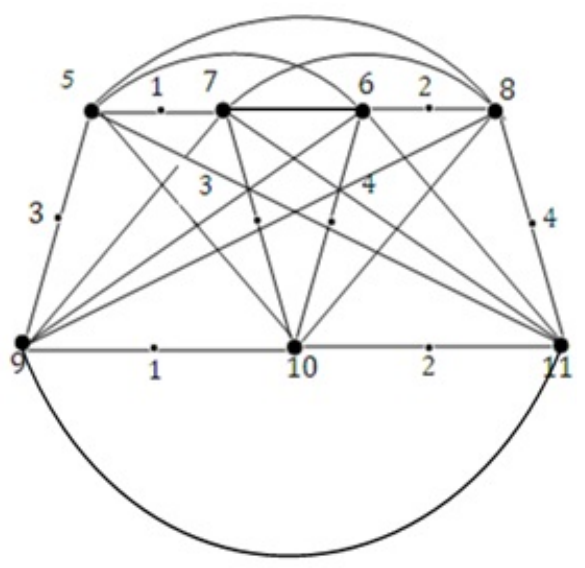

FIGURE 1. $C\left(Q_{3}\right)$ with coloring, $\chi_{H}\left(C\left(Q_{3}\right)\right)=11$.

from above each $c\left(v_{i}\right), c\left(w_{i}\right), c\left(u_{i}\right)$ and its neighbors are assigned by different colors i.e. $c\left(v_{i}\right) \neq c\left(w_{i}\right) \neq c\left(u_{i}\right)$, although $c\left(v_{i}^{\prime}\right)=c\left(v_{i}^{\prime \prime \prime \prime}\right)$ and $c\left(v_{i}^{\prime \prime}\right)=c\left(v_{i}^{\prime \prime \prime}\right)$ but these vertices are at least at a distance 2 , therefore it is proper. It is also obvious from above that no two edges share the same color pair and same colored vertices are at least at a distance 3, therefore it is harmonious and all the vertices are colored by $5 n-4$ colors. Now if we repeat (assign) any color on any vertex from these $5 n-4$ colors, color pairs will be repeated which leads to contradict the harmonious 
coloring, therefore it is minimum. Hence $\chi_{H}\left(C\left(Q_{n}\right)\right)=5 n-4$. Figure 1 shows the central graph of $Q_{3}$ with harmonious coloring.

Theorem 2.2. For central graph of double quadrilateral snake $D Q_{n}$, the harmonious chromatic number, $\chi_{H}\left(C\left(D Q_{n}\right)\right)=8 n-7, n \geq 2$

Proof. Let us consider $D Q_{n}$ as the double quadrilateral snake and $P_{n}$ as the path graph with $n$ vertices $u_{1}, u_{2}, \ldots, u_{n}$. Now we obtain the central graph as described in Theorem 2.1, therefore $V\left(C\left(D Q_{n}\right)\right)=\left\{u_{i}: 1 \leq i \leq n\right\} \cup\left\{v_{i}, w_{i}, x_{i}, y_{i}, e_{i}^{\prime}, e_{i}^{\prime \prime}, e_{i}, l_{i}^{\prime}, l_{i}^{\prime \prime}\right.$, $\left.m_{i}^{\prime}, m_{i}^{\prime \prime}: 1 \leq i \leq n-1\right\}$. Now coloring the vertices of $C\left(D Q_{n}\right)$ as follows; define $c: V\left(C\left(D Q_{n}\right)\right) \longrightarrow\{1,2,3, \ldots, 8 n-7\}$ for $n \geq 2$ by $c\left(e_{i}\right)=i, c\left(e_{i}^{\prime}\right)=i, c\left(e_{i}^{\prime \prime}\right)=i$, $c\left(l_{i}^{\prime}\right)=n-1+i, c\left(l_{i}^{\prime \prime}\right)=n-1+i, c\left(m_{i}^{\prime}\right)=2 n-2+i, c\left(m_{i}^{\prime \prime}\right)=2 n-2+i$, $c\left(v_{i}\right)=3 n-3+i, c\left(w_{i}\right)=4 n-4+i, c\left(x_{i}\right)=5 n-5+i, c\left(y_{i}\right)=6 n-6+i$ for $(1 \leq i \leq n-1)$ and $c\left(u_{i}\right)=7 n-7+i$ for $(1 \leq i \leq n)$. To prove $\mathrm{c}$ is harmonious and minimum, follow Theorem 2.1. Figure 2 shows the harmonious coloring for $C\left(D Q_{3}\right)$.

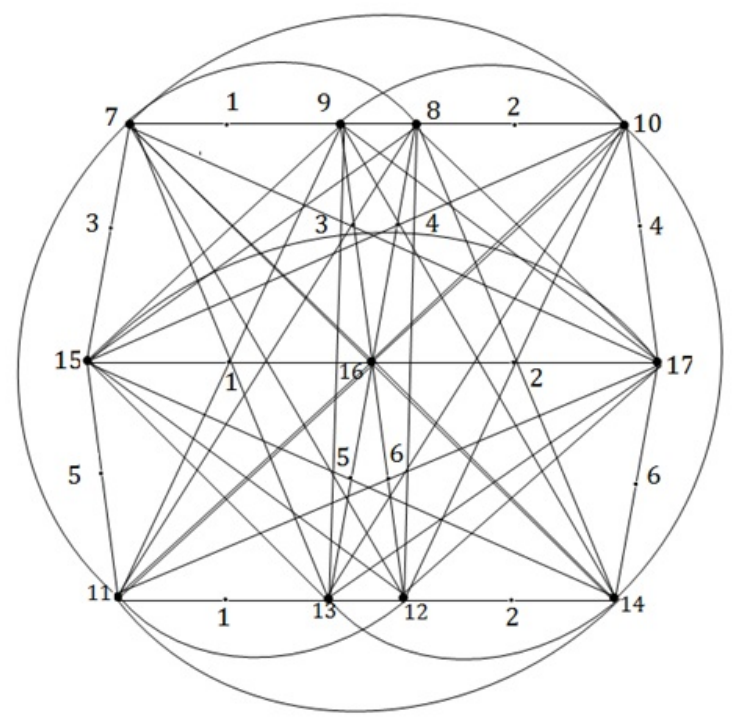

Figure 2. $C\left(D Q_{3}\right)$ with harmonious coloring, $\chi_{H}\left(C\left(D Q_{3}\right)\right)=17$.

Theorem 2.3. For central graph of triple quadrilateral snake $T Q_{n}$, the harmonious chromatic number, $\chi_{H}\left(C\left(T Q_{n}\right)\right)=11 n-10, n \geq 2$.

Proof. Let us consider $T Q_{n}$ as the triple quadrilateral snake and $P_{n}$ as the path graph with $n$ vertices $u_{1}, u_{2}, \ldots, u_{n}$. Now we obtain the central graph as described in Theorem 2.1, therefore $V\left(C\left(T Q_{n}\right)\right)=\left\{u_{i}: 1 \leq i \leq n\right\} \cup\left\{v_{i}, w_{i}, x_{i}, y_{i}, p_{i}, q_{i}, e_{i}, e_{i}^{\prime}, e_{i}^{\prime \prime}\right.$, $\left.e_{i}^{\prime \prime \prime}, l_{i}^{\prime}, l_{i}^{\prime \prime}, m_{i}^{\prime}, m_{i}^{\prime \prime}, z_{i}^{\prime}, z_{i}^{\prime \prime}: 1 \leq i \leq n-1\right\}$. Now coloring the vertices of $C\left(T Q_{n}\right)$ as follows; define $c: V\left(C\left(T Q_{n}\right)\right) \longrightarrow\{1,2,3, \ldots, 11 n-10\}$ where $n \geq 2$ by $c\left(e_{i}\right)=i$, 
$c\left(e_{i}^{\prime}\right)=i, c\left(e_{i}^{\prime \prime}\right)=i, c\left(e_{i}^{\prime \prime \prime}\right)=i, c\left(l_{i}^{\prime}\right)=n-1+i, c\left(l_{i}^{\prime \prime}\right)=n-1+i, c\left(m_{i}^{\prime}\right)=2 n-2+i$, $c\left(m_{i}^{\prime \prime}\right)=2 n-2+i, c\left(z_{i}^{\prime}\right)=3 n-3+i, c\left(z_{i}^{\prime}\right)=3 n-3+i, c\left(v_{i}\right)=4 n-4+i$, $c\left(w_{i}\right)=5 n-5+i, c\left(x_{i}\right)=6 n-6+i, c\left(y_{i}\right)=7 n-7+i, c\left(p_{i}\right)=8 n-8+i$, $c\left(y_{i}\right)=9 n-9+i, c\left(y_{i}\right)=10 n-10+i$ for $(1 \leq i \leq n-1)$ and $c\left(u_{i}\right)=10 n-10+i$ for $(1 \leq i \leq n)$. For remaining proof, follow Theorem 2.1. Figure 3 shows the harmonious coloring for $C\left(T Q_{3}\right)$.

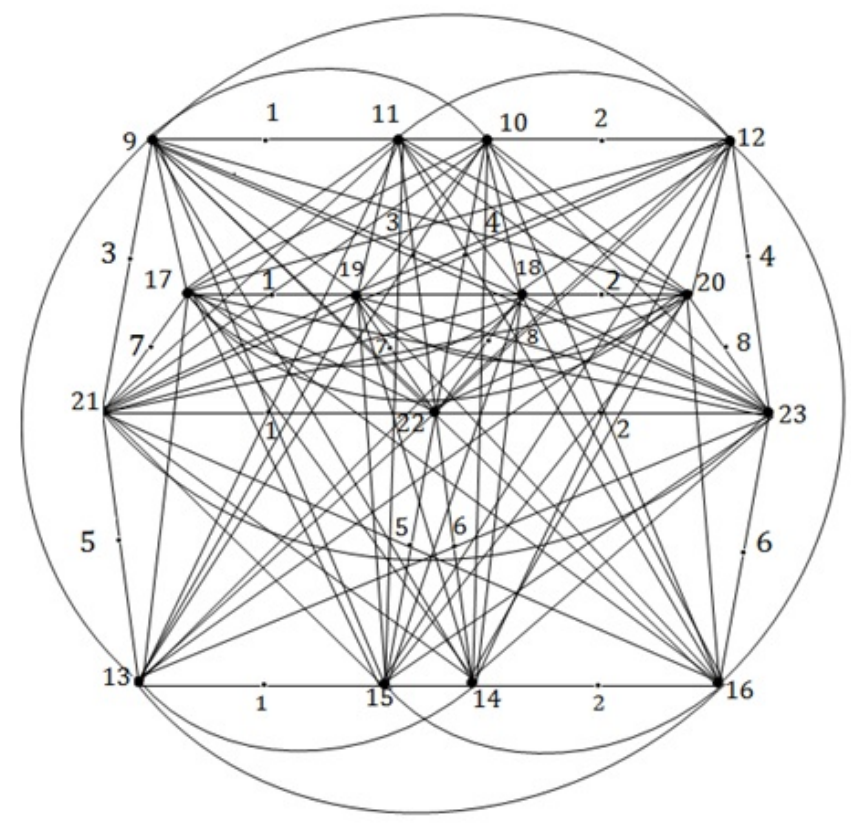

Figure 3. $C\left(T Q_{3}\right)$ with harmonious coloring, $\chi_{H}\left(C\left(T Q_{3}\right)\right)=23$.

\section{Harmonious Chromatic Number of $k$-Quadrilateral Snake}

Theorem 3.1. For central graph of $k$-quadrilateral snake $k Q_{n}$, the harmonious chromatic number, $\chi_{H}\left(C\left(k Q_{n}\right)\right)=(3 k+2) n-(3 k+1), n \geq 2$.

Proof. For $k=1$, we have $\chi_{H}\left(C\left(Q_{n}\right)\right)=5 n-4$, this proves Theorem 2.1, for $k=2$, we have $\chi_{H}\left(C\left(D\left(Q_{n}\right)\right)\right)=8 n-7$, this proves Theorem 2.2 , for $k=3$, we have $\chi_{H}\left(C\left(T\left(Q_{n}\right)\right)\right)=11 n-10$, this proves Theorem 2.3, which is true.

Let $\chi_{H}\left(C\left(k Q_{n}\right)\right)$ be true for some positive integer $r$, i.e. $\chi_{H}\left(C\left(r Q_{n}\right)\right)=$ $(3 r+2) n-(3 r+1)$. We shall now prove that $\chi_{H}\left(C\left((r+1) Q_{n}\right)\right)$ is true.

Consider $\chi_{H}\left(C\left((r+1) Q_{n}\right)\right)=(3(r+1)+2) n-(3(r+1)+1)=(3 r+2) n-(3 r+1)+3 n-$ $3=\chi_{H}\left(C\left(r Q_{n}\right)\right)+11 n-10-(8 n-7)=\chi_{H}\left(C\left(r Q_{n}\right)\right)+\chi_{H}\left(C\left(T Q_{n}\right)\right)-\chi_{H}\left(C\left(D Q_{n}\right)\right)$ which is true. Therefore it is true for $r+1$ that follows by mathematical induction, it is true for all values of $k$. Hence the theorem. 


\section{Harmonious Chromatic Number of $C\left(A Q_{n}\right), C\left(D A Q_{n}\right), C\left(T A Q_{n}\right)$}

Theorem 4.1. For alternate quadrilateral snake $A Q_{n}$, harmonious chromatic number, $\chi_{H} C\left(A Q_{n}\right)=\frac{7 n}{2}-1, n$ is even and $\geq 4$.

Proof. Let us consider $A Q_{n}$ as the alternate quadrilateral snake and $P_{n}$ as the path graph with $n$ vertices $u_{1}, u_{2}, \ldots, u_{n}$. Now we obtain the central graph as described in Theorem 2.1, therefore $V\left(C\left(A Q_{n}\right)\right)=\left\{u_{i}: 1 \leq i \leq n\right\} \cup\left\{v_{i}, w_{i}, v_{i}^{\prime \prime}, l_{i}^{\prime}, l_{i}^{\prime \prime}:(1 \leq i \leq\right.$ $\left.\left.\frac{n}{2}\right)\right\} \cup\left\{v_{i}^{\prime}:(1 \leq i \leq n-1)\right\}$. Now coloring the vertices of $C\left(A Q_{n}\right)$ as follows; define $c: V\left(C\left(A Q_{n}\right) \longrightarrow\left\{1,2,3, \ldots, \frac{7 n}{2}-1\right\}\right.$ where $n \geq 4$ by $c\left(v_{i}^{\prime}\right)=i$ for $(1 \leq i \leq n-1)$, $c\left(v_{i}^{\prime \prime}\right)=i, c\left(l_{i}^{\prime}\right)=n-1+i, c\left(l_{i}^{\prime \prime}\right)=n-1+i, c\left(v_{i}\right)=\frac{3 n}{2}-1+i, c\left(w_{i}\right)=2 n-1+i$ for $\left(1 \leq i \leq \frac{n}{2}\right)$ and $c\left(u_{i}\right)=\frac{5 n}{2}-1+i$ for $(1 \leq i \leq n)$. To prove $\mathrm{c}$ is harmonious and minimum, follow Theorem 2.1. Figure 4 shows the central graph of $A Q_{n}$ with harmonious coloring.

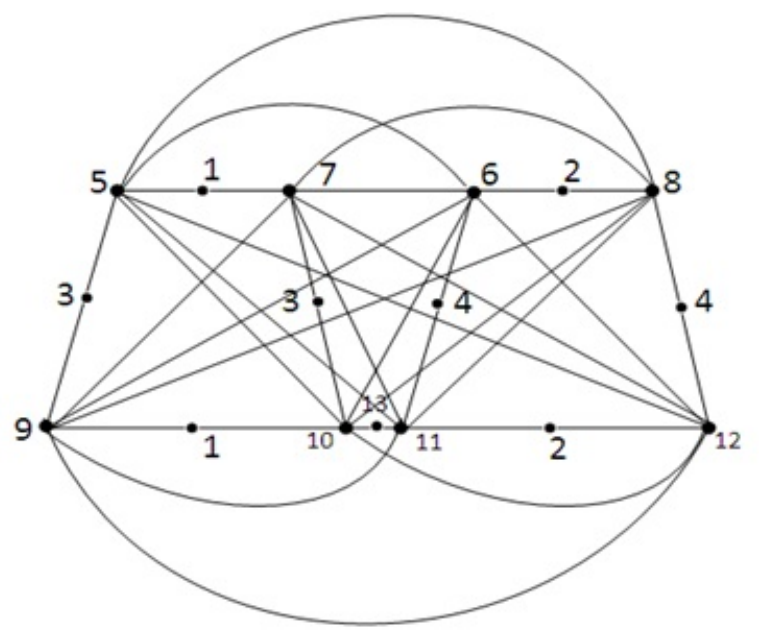

Figure 4. $C\left(A Q_{4}\right)$ with harmonious coloring, $\chi_{H}\left(C\left(A Q_{4}\right)\right)=13$.

Theorem 4.2. For central graph of double alternate quadrilateral snake $D\left(A Q_{n}\right)$, the harmonious chromatic number, $\chi_{H}\left(C\left(D\left(A Q_{n}\right)\right)\right)=5 n-1, n$ is even and $\geq 4$.

Proof. Let us consider $D\left(A Q_{n}\right)$ as the double alternate quadrilateral snake and $P_{n}$ as the path graph with $n$ vertices $u_{1}, u_{2}, \ldots, u_{n}$. Now we obtain the central graph as described in Theorem 2.1, therefore $V\left(C\left(D\left(A Q_{n}\right)\right)\right)=\left\{u_{i}: 1 \leq i \leq\right.$ $n\} \cup\left\{v_{i}, w_{i}, x_{i}, y_{i}, e_{i}^{\prime}, e_{i}^{\prime \prime}, l_{i}^{\prime}, l_{i}^{\prime \prime}, m_{i}^{\prime}, m_{i}^{\prime \prime}:\left(1 \leq i \leq \frac{n}{2}\right)\right\} \cup\left\{e_{i}:(1 \leq i \leq n-1)\right\}$. Now coloring the vertices of $C\left(D\left(A Q_{n}\right)\right)$ as follows; define $c: V\left(C\left(D\left(A Q_{n}\right)\right) \longrightarrow\right.$ $\{1,2,3, \ldots, 5 n-1\}$ where $n \geq 4$ by $c\left(e_{i}\right)=i$ for $(1 \leq i \leq n-1), c\left(e_{i}^{\prime}\right)=i, c\left(e_{i}^{\prime \prime}\right)=i$, $c\left(l_{i}^{\prime}\right)=n-1+i, c\left(l_{i}^{\prime \prime}\right)=n-1+i, c\left(m_{i}^{\prime}\right)=\frac{3 n}{2}-1+i, c\left(m_{i}^{\prime \prime}\right)=\frac{3 n}{2}-1+i$, $c\left(v_{i}\right)=2 n-1+i, c\left(w_{i}\right)=\frac{5 n}{2}-1+i, c\left(x_{i}\right)=3 n-1+i, c\left(y_{i}\right)=\frac{7 n}{2}-1+i$ for 
$\left(1 \leq i \leq \frac{n}{2}\right)$ and $c\left(u_{i}\right)=4 n-1+i$ for $(1 \leq i \leq n)$. To prove $\mathrm{c}$ is harmonious and minimum, follow Theorem 2.1. Figure 5 shows the central graph of $D\left(A Q_{n}\right)$ with harmonious coloring.

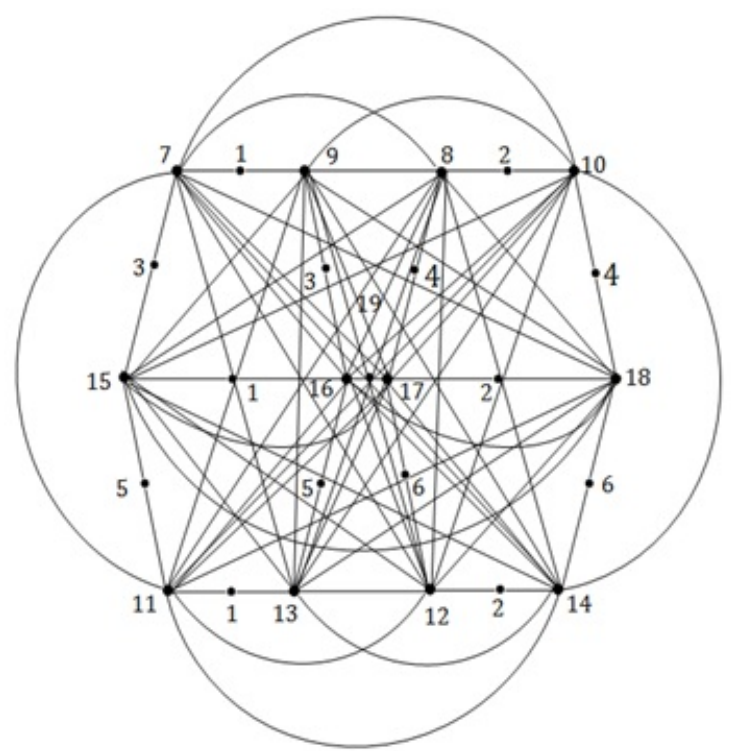

FiguRE 5. $C\left(D\left(A Q_{4}\right)\right)$ with coloring, $\chi_{H}\left(C\left(D\left(A Q_{4}\right)\right)\right)=19$.

Theorem 4.3. For triple alternate Quadrilateral snake $T\left(A Q_{n}\right)$, the harmonious chromatic number, $\chi_{H} C\left(T\left(A Q_{n}\right)\right)=\frac{13 n}{2}-1, n$ is even and $\geq 4$.

Proof. Let us consider $T\left(A Q_{n}\right)$ as the triple alternate quadrilateral snake and $P_{n}$ as the path graph with $n$ vertices $u_{1}, u_{2}, \ldots, u_{n}$. Now we obtain the central graph as described in Theorem 2.1, therefore $V\left(C\left(T\left(A Q_{n}\right)\right)\right)=\left\{u_{i}: 1 \leq i \leq n\right\} \cup$ $\left\{v_{i}, w_{i}, x_{i}, y_{i}, p_{i}, q_{i}, e_{i}^{\prime}, e_{i}^{\prime \prime}, e_{i}^{\prime \prime \prime}, l_{i}, l_{i}^{\prime}, l_{i}^{\prime \prime}, m_{i}, m_{i}^{\prime}, m_{i}^{\prime \prime}:\left(1 \leq i \leq \frac{n}{2}\right)\right\} \cup\left\{e_{i}:(1 \leq i \leq n-\right.$ $1\}$. Now coloring the vertices of $C\left(T\left(A Q_{n}\right)\right)$ as follows; define $c: V\left(C\left(T\left(A Q_{n}\right)\right) \longrightarrow\right.$ $\left\{1,2,3, \ldots, \frac{13 n}{2}-1\right\}$ for $n \geq 4$ by $c\left(e_{i}\right)=i$ for $(1 \leq i \leq n-1), c\left(e_{i}^{\prime}\right)=i, c\left(e_{i}^{\prime \prime}\right)=i$, $c\left(e_{i}^{\prime \prime \prime}\right)=i, c\left(l_{i}^{\prime}\right)=n-1+i, c\left(l_{i}^{\prime \prime}\right)=n-1+i, c\left(m_{i}^{\prime}\right)=\frac{3 n}{2}-1+i, c\left(m_{i}^{\prime \prime}\right)=\frac{3 n}{2}-1+i$, $c\left(l_{i}\right)=2 n-1+i, c\left(m_{i}\right)=2 n-1+i, c\left(v_{i}\right)=\frac{5 n}{2}-1+i, c\left(w_{i}\right)=3 n-1+i$, $c\left(x_{i}\right)=\frac{7 n}{2}-1+i, c\left(y_{i}\right)=4 n-1+i, c\left(p_{i}\right)=\frac{9 n}{2}-1+i, c\left(q_{i}\right)=5 n-1+i$ for $\left(1 \leq i \leq \frac{n}{2}\right)$ and $c\left(u_{i}\right)=\frac{11 n}{2}-1+i$ for $(1 \leq i \leq n)$. To prove $\mathrm{c}$ is harmonious and minimum, follow Theorem 2.1. Figure 6 shows the central graph of $T\left(A Q_{n}\right)$ with harmonious coloring. 


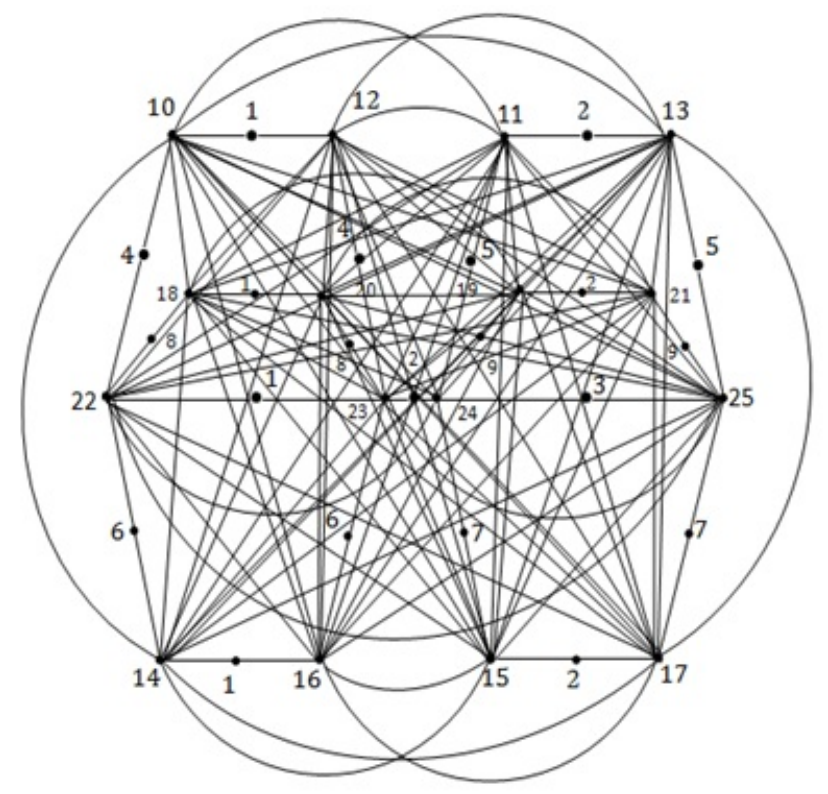

FiguRE 6. $C\left(T\left(A Q_{4}\right)\right)$ with harmonious coloring, $\chi_{H}\left(C\left(T\left(A Q_{4}\right)\right)\right)=25$.

5. Harmonious Chromatic Number of $k$-Alternate Quadrilateral SNAKE

Theorem 5.1. For central graph of $k$-alternate quadrilateral snake $k\left(A Q_{n}\right)$, the harmonious chromatic number, $\chi_{H}\left(C\left(k\left(A Q_{n}\right)\right)\right)=\left(\frac{3 k+4}{2}\right) n-1, n$ is even and $\geq 4$.

Proof. For $k=1$, we have $\chi_{H}\left(C\left(A Q_{n}\right)\right)=\frac{7 n}{2}-1$, this proves Theorem 4.1, for $k=2$, we have $\chi_{H}\left(C\left(D\left(A Q_{n}\right)\right)\right)=5 n-1$, this proves Theorem 4.2 , for $k=$ 3 , we have $\chi_{H}\left(C\left(T\left(A Q_{n}\right)\right)\right)=\frac{13 n}{2}-1$, this proves Theorem 4.3 which is true. Let $\chi_{H}\left(C\left(k\left(A Q_{n}\right)\right)\right)$ be true for some positive integer $r$, i.e. $\chi_{H}\left(C\left(r\left(A Q_{n}\right)\right)\right)=$ $\left.\left(\frac{3 r+4}{2}\right) n-1\right)$. We shall now prove that $\chi_{H}\left(C\left((r+1)\left(A Q_{n}\right)\right)\right)$ is true. Consider $\left.\left.\chi_{H}\left(C\left((r+1) A Q_{n}\right)\right)=\left(\frac{3(r+1)+4}{2}\right) n-1\right)=\left(\frac{3 r+4}{2}\right) n-1\right)+\frac{3 n}{2}=\chi_{H}\left(C\left(r A Q_{n}\right)\right)+$ $\left(\frac{13 n}{2}-1\right)-(5 n-1)=\chi_{H}\left(C\left(r\left(A Q_{n}\right)\right)\right)+\chi_{H}\left(C\left(T\left(A Q_{n}\right)\right)\right)-\chi_{H}\left(C\left(D\left(A Q_{n}\right)\right)\right)$ which is true. Therefore it is true for $r+1$ that follows by mathematical induction, it is true for all values of $k$. Hence the theorem.

\section{Conclusion}

This article shows the study about the harmonious coloring and we find the harmonious chromatic number of central graph of $k$ - quadrilateral and $k$-alternate quadrilateral snakes $\chi_{H}\left(C\left(k Q_{n}\right)\right)=(3 k+2) n-(3 k+1)$, and $\chi_{H}\left(C\left(k\left(A Q_{n}\right)\right)\right)=$ 
$\left(\frac{3 k+4}{2}\right) n-1$ respectively. For future scope we can examine the different type of colorings for these quadrilateral snakes.

\section{ACKNOWLEDGMENT}

Thanks for the referees for their excellent comments and valuable suggestions for improving this article.

\section{REFERENCES}

[1] Agasthi P., Parvathi N., On some labeling of quadrilateral snake, Int. J. Pure Appl. Math., 119(12), (2018), 2975-2992.

[2] Bondy J.A. and Murty U.S.R., Graph Theory with Applications, London: MacMillan, (1976).

[3] Gallian J.A., A dynamic survey of graph labeling, The Elec. J. Combin., (2019), \#DS6

[4] Gopi R., Odd sum labeling of alternative quadrilateral snake, Int. J. EnginSci., Advan. Comput. and Bio-Tech. , 7(3),(2016), 73-77.

[5] Harary F., Graph Theory, Narosa Publishing home, (1969).

[6] Hopcroft J. and Krishnamoorthy M.S., On the harmonious coloring of graphs, SIAM J. Algebra Discrete Math., 4, (1983), 306-311.

[7] Mansuri A., On harmonious chromatic number of triple star graph, J. Hyper., 5(1), (2016), 26-32.

[8] Miller Z. , Pritikin D., The harmonious coloring number of a graph, Discrete Math., 93, (1991), 211-228.

[9] Ponraj R. and Narayanan S. S., Difference Cordiality of Some Snake Graphs obtained from double alternate snake graphs, Global J. Math. Sci.: Theory and Practical, (5), (2013), 167-175.

[10] Ponraj R. and Narayanan S. S., Difference Cordiality of Some Snake Graphs, J. Appl. Math.E Inform., 32(3-4), (2014), 377-387.

[11] Ponraj R. and Narayanan S. S., Difference Cordiality of Some derived Graphs, J. Math. Comb., (4), (2013), 37-48.

[12] Ponraj R. and Narayanan S. S. and Kala R., Difference cordial labeling of graphs obtained from double snakes, Int. J. Math. Res., (5), (2013), 317-322.

[13] Rathod N. B. and Kanani K. K. , V4-cordial labeling of quadrilateral snakes, Int. J. Emerging Tech. Appl. Eng., Tech., Sci., (9), (2016), 45-51.

[14] Sandhya S. S. , Ebin R. M. E. and Deepa S.D., Heronian Mean Labeling of Triple Triangular and Triple Quadrilateral Snake Graphs, Int. J. Appl. Math. Sci. , 9(2), (2016), 177-186.

[15] Sandhya S. S. , Raja Merly E. and Shiny B. , Subdivision of super geometric mean labeling for quadrilateral snake graphs, Int. J. Math. Trends Tech. , 24(1), (2015), 1-16.

[16] Sandhya S. S. , Raja Merly E. and Shiny B. , Super geometric mean labeling on double quadrilateral snake graphs, Asian Pacific J. Res., 1(XXI), (2015), 128-135.

[17] Venkatachalam M. , Vernold Vivin J. and Kaliraj K., Harmonious Coloring On Double Star Graph families, Tamkang J. Math., 43(2),(2012), 153-158.

[18] Vernold Vivin J. And Thilagavathi K. , On Harmonious Colouring of Line Graph of Central Graph of Paths , Appl. Math. Sci., 3(5),(2009), 205-214. 